\title{
EFEKTIFITAS BLENDED LEARNING DALAM MATA KULIAH PEMBELAJARAN SAINS ANAK USIA DINI TERHADAP KREATIFITAS MAHASISWA PG-PAUD STKIP SYEKH MANSHUR DENGAN MENGGUNAKAN APLIKASI SIGIL
}

\author{
Badri Munawar', Gasam Tarmon², Rihatul Jannah ${ }^{3}$ \\ 1,2,3 STKIP Syekh Manshur, Pandeglang, Indonesia \\ 1badri.munawar02@gmail.com, ${ }^{2}$ gasAMMANIPA@gmail.com, ${ }^{3}$ reehat085@gmail.com
}

\begin{abstract}
ABSTRAK
Penelitian ini dilatar belakangi oleh kurangnya kreatifitas mahasiswa PG-PAUD dalam memahami pembelajaran sains anak usia dini pada saat pandemi seperti ini dalam pembelajaran yang menggunakan model blended learning. Penelitian ini bertujuan untuk menguji coba secara terbatas efektivitas blended learning dalam mata kuliah sains anak usia dini terhadap kreativitas mahasiswa PG-PAUD STKIP Syekh Manshur dengan menggunakan aplikasi sigil. Untuk menjawab pertanyaan tersebut dilakukan penelitian dengan pendekatan kuantitatif. Penelitian tersebut menggunakan metode quasy eksperimental dengan jenis pretest-posttest group design. Desain penelitian menggunakan dua kelas, yaitu kelas eksperimen dan kelas kontrol. Perlakuan yang diberikan pada eksperimen, adalah blended learning dengan menggunakan aplikasi sigil (X1) dan pada kelas kontrol, yaitu model konvensional (X2) . Berdasarkan hasil dari uji Ancova nilai $F_{\text {hitung }}>F_{\text {tabel }}(15.49>3.98)$, maka dapat dinyatakan terdapat perbedaan rata-rata kreatifitas mahasiswa pada kelas eksperimen dan kelas kontrol artinya blended learning berbasis aplikasi sigil memberikan pengaruh yang signifikan terhadap kreatifitas mahasiswa, serta lebih efektif untuk meningkatkan kreatifitas mahasiswa, hal ini ditunjukkan dengan adanya perbedaaan rata-rata N-Gain pada kelas eksperimen 0.88 dengan kategori tinggi dan kelas kontrol 0.66 dengan kategori sedang.
\end{abstract}

Kata Kunci: blended learning, pengembangan sains anak usia dini, kratifitas, sigil

\section{THE EFFECTIVENESS OF BLENDED LEARNING IN THE EARLY CHILDHOOD SCIENCE LEARNING COURSE ON THE STUDENTS' CREATIVITY THROUGH SIGIL APPLICATION AT PG-PAUD STUDY PROGRAM OF STKIP SYEKH MANSHUR}

\begin{abstract}
This research was motivated by the lack of creativity of PG-PAUD students in understanding early childhood science learning during the pandemic in learning using blended learning models. This research aimed to test the effectiveness of blended learning in the early childhood science course on the students' creativity at PG-PAUD STKIP Shekh Manshur by using the sigil application. To answer the research question, this research was conducted by a quantitative approach. The study used a quasi-experimental method with a type of pretest-posttest group design. The research design used two classes, namely the experimental class and the control class. The treatment given to the experimental class was blended learning through the application of sigil (X1) and the control class was taught by the conventional model (X2). Based on the results of the Ancova test, the score of $F_{\text {count }}>F_{\text {table }}(15.49$ > 3.98). Thus, there was a difference in the average score of students' creativity in the experimental class and the control classes. It meant that blended learning based on sigil application significantly influenced the students' creativity. Then, blended learning based on sigil application was also more effective to increase students' creativity, which was indicated by the difference in the average of $N$-Gain in the experimental class (0.88) with high category and in the control class $(0.66)$ in the moderate category.
\end{abstract}

Keywords: blended learning, early childhood science development, creativity, sigil

\begin{tabular}{|c|c|c|}
\hline Submitted & Accepted & Published \\
\hline 21 September 2021 & 03 Desember 2021 & 24 Januari 2022 \\
\hline
\end{tabular}

\begin{tabular}{|l|c|r|}
\hline Citation & $:$ & $\begin{array}{r}\text { Munawar, B., Tarmon, G., \& Jannah, R. (2021). Efektifitas Blended Learning dalam Mata Kuliah Pembelajaran Sains } \\
\text { Anak Usia Dini terhadap Kreatifitas Mahasiswa PG-Paud STKIP Syekh Manshur dengan Menggunakan Aplikasi } \\
\text { Sigil. Jurnal PAJAR (Pendidikan dan Pengajaran), 6(1), 68-75. DOI : http://dx.doi.org/10.33578/pjr.v6i1.8567. }\end{array}$ \\
\hline
\end{tabular}

\section{PENDAHULUAN}

Mata Kuliah Pembelajaran sains untuk anak usia dini difokuskan pada pembelajaran mengenai diri sendiri, alam sekitar, dan gejala alam. Pembelajaran sains pada anak usia dini memiliki beberapa tujuan, diantaranya yaitu: (1) membantu pemahaman anak tentang konsep sains dan keterkaitannya dengan kehidupan sehari-hari, (2) membantu menumbuhkan minat pada anak usia dini untuk mengenal dan memperlajari bendabenda serta kejadian di lingkungan sekitarnya, (3) membantu anak agar mampu menerapkan berbagai konsep sains untuk menjelaskan gejala- 
gejala alam, (4) membantu anak usia dini untuk dapat mengenal dan memupuk rasa cinta kepada alam sekitar sehingga menyadari keagungan Tuhan Yang Maha Esa ( Leeper :1994)

Perkuliahan Mata Kuliah Pembelajaran sains anak usia dini hakikatnya memberikan pengetahuan dan pengalaman kepada mahasiswa untuk di implementasikan kembali pada saat mahasiswa menjadi guru anak usia dini terhadap pemahaman sains. Pada saat pandemi seperti ini sepertinya metode pembelajaran konvensional tidak tepat digunakan dalam pembelajaran blended learning karena dengan metode ceramah kurang efektif jika diterapkan dalam mata kuliah pembelajaran sains anak usia dini. Oleh karena itu, dosen harus memilih model yang cocok dalam pembelajaran pada saat pandemi. Penggunaan aplikasi sigil merupakan salah satu solusi untuk dikombinasikan dengan model pembelajaran blended learning.

Dari hasil survey yang dilakukan oleh peneliti terhadap mahasiswa PG_PAUD ternyata dalam pembelajaran daring yang hanya diberikan materi saja ternyata masih sulit untuk menunjang atau meningkatkan kreatifitas mahasiswa dalam pembelajaran sains. Kualitas sebuah proses pembelajaran harus tetap diutamakan oleh dosen maupun mahasiswa, dengan segala kendala atau halangan yang ada. Dengan menggunakan pembelajaran blended learning yang mengutamakan $70 \%$ pembelajaran menggunakan dalam jaringan (daring) dan $30 \%$ pembelajaran menggunakan luar jaringan (luring), maka dari itu mahasiswa harus dapat meningkatkan kreatifitas pembelajaran sains anak usia dini pada saat pandemi. Oleh sebab itu peneliti tertarik untuk melakukan penelitian yang berkaitan dengan efektifitas blended learning dalam mata kuliah pembelajaran sains anak usia dini terhadap kreatifitas mahasiswa PG-PAUD STKIP Syekh Manshur dengan menggunakan aplikasi sigil.

Berdasarkan permasalahan diatas terkait efektivitas blended learning dalam pembelajaran sain anak usia dini terhadap kreativitas Mahasiswa PG-PAUD, peneliti melakukan tinjauan pustaka dari berbagi permasalahan seputar efektivitas pembelajaran blended learning. Sama seperti permasalahan yang peniliti temukan dilapangan, berdasarkan tinjauan pustaka diatas didapat bahwa efektivitas blended learning hanya mencakup penguasaan konsep, tidak sampai ke kreativitas, pada model blended learning hanya meningkatkan efektivitas dan tidak meningkatkan kreativitas mahasiswa, model blended learning yang dikembangakan mencakup E-Learning tidak sampai membahas efektivitas dan peningkatan kreativitas mahasiswa, Mengukur efektivitas EModul tidak mencakup model pembelajaran blended learning.

Berdasarkan tinjauan pustaka tersebut, maka peneliti tertarik untuk melakukan penelitian terkait efektivitas blended learning dalam mata kuliah pembelajaran sains anak usia dini terhadap kreativitas mahasiswa dengan menggunakan aplikasi sigil. Efektivitas blended learning memiliki tujuan untuk memadukan pola pembelajaran jarak jauh pada saat pandemi sehingga meningkatkan kreativitas mahasiswa dalam pembelajaran sains anak usia dini, dalam prosesnya dengan menggunakan aplikasi sigil.

\section{KAJIAN TEORETIS}

\section{Pembelajaran Sains Anak Usia Dini}

Sains menurut Kilmer dan Hofman (1995) merupakan pengetahuan tentang fenomenafenomena tertentu, proses yang digunakan untuk mengumpulkan dan mengevaluasi informasi, dan sebagai bentuk adaptasi manusia pada lingkungan. Sains bukan hanya kumpulan fakta dan hafalan rumus saat belajar melainkan juga mencakup prinsip-prinsip, prosedur, dan sikap ilmiah. Sains juga dipandang sebagai suatu proses mencari tahu alam secara sistematis untuk mengetahui suatu pengetahuan. Pembelajaran sains dalam pendidikan anak usia dini merupakan serangkaian kegiatan belajar yang menyenangkan untuk menstimulus anak mengeksplorasi lingkungan mereka dan merefleksikan hasil pengamatan dan penemuan mereka. Cara ini juga merupakan pendekatan terpadu di mana anak-anak pada saat itu sedang berpikir dan membangun pemahaman dasar tentang dunia.

\section{Kreativitas}

Kreativitas adalah suatu pola tingkah laku siswa yang aktif, memiliki keingintahuan yang besar, yang tidak bisa diam dalam suatu hal serta 
dorongan untuk berkembang dalam diri sendiri maupun orang lain. Kemudian didukung dari beberapa para ahli pengertian tentang kreativitas, Menurut Suyanto \& Asep Djihad dalam Istirani dan Intan Pulungan (2017:131) bahwa ada beberapa makna popular tentang istilah kreativitas : Pertama, kreativitas mengupayakan untuk membuat sesuatu hal yang baru dan berbeda. Kedua, kreativitas dianggap sebagai sesuatu yang baru dan asli itu merupakan hasil yang kebetulan. Ketiga, kreativitas dipahami dari sesuatu apa saja yang tercipta sebagai yang baru dan berbeda. Keempat, kreativitas merupakan sesuatu proses yang unik. Kelima, kreativitas membutuhkan kecerdasan yang tinggi. Keenam, kreativitas merupakan suatu kemampuan yang dipengaruhi oleh faktor bawaan. Selanjutnya menurut Rogers dalam Utami Munandar (2014:18) bahwa "kreativitas adalah kecenderungan untuk mengaktualisasi diri, mewujudkan potensi, dorongan untuk berkembang dan menjadi matang, kecenderungan untuk mengekspresikan dan mengaktifkan semua kemampuan organisme". Demikian pula Clark Moustakis dalam Utami Munandar (2014:18) menyatakan bahwa "kreativitas adalah pengalaman mengekspresikan dan mengaktualisasikan identitas individu dalam bentuk terpadu dalam hubungan dengan diri sendiri, dengan alam,dan dengan orang lain". Menurut Sternberg dalam Utami Munandar (2014:20), yaitu "kreativitas adalah titik pertemuan yang khas antara tiga atribut psikologis: inteligensi, gaya kognitif, dan kepribadian/motivasi". Selanjutnya Menurut Reni Akbar dalam Latifah Husien (2017:82) "kreativitas adalah kemampuan seseorang melahirkan sesuatu yang baru atau kombinasi hal yang sudah ada sehingga terkesan ada".

\section{Aplikasi Sigil}

Sebagai aplikasi lintas platform, Sigil didistribusikan untuk platform Windows, macOS , Haiku dan Linux di bawah lisensi GNU GPL . Sigil mendukung pengeditan berbasis kode file EPUB, serta impor file HTML dan teks biasa. Aplikasi pendamping, PageEdit, memungkinkan pengeditan file EPUB oleh WYSIWYG . Sigil telah dikembangkan oleh Strahinja Val Marković dan lainnya sejak 2009. Dari Juli 2011 hingga Juni
2015 John Schember adalah pengembang utama. Pada Juni 2015 pengembangan Sigil diambil alih oleh Kevin Hendricks dan Doug Massay. Buku elektronik atau lazim disebut dengan eBook merupakan salah satu alternatif yang dapat dipilih untuk membudayakan minat baca masyarakat umu tidak hanya untuk kalangan pelajar saja. eBook ini lebih bersifat modern dan menarik minat baca karena di dalam eBook disediakan fitur-fitur yang dapat terisi teks, gambar sampai dapat diisi dengan suara untuk membantu memudahkan penyampaian isi buku dan memudahkan memahaman para pembaca. eBook dipublikasikan dalam bentuk digital sehingga memudahkan para penulis buku dalam membuat dan mempublikasikan hasil penulisannnya.

Sigil merupakan software editor yang editor untuk epub yang bersifat open source. Epub (electronic publication) merupakan salah satu format digital yang merupakan format standardisasi bentuk yang diperkenalkan oleh International Digital Publishing Forum (IDPF) pada tahun 2011. Epub merupakan software pengganti dari Open eBook yang bertugas sebagai format buku terbuka. Epub merupakan file multimedia yang dapat di diakses dari file bertipe htlm, xhtml, xml, css yang dijadikan satu file dengan ekstensi .epub Format epub merupakan format buku digital yang paling populer saat ini. Hal ini disebabkan karena pada epub terdapat berbagai fitur yang dapat digunakan untuk memodifikasi tampilan eBook. Seperti tersedianya perintah yang digunakan untuk penyisipkan file video dan audio selain gambar dan teks, sehingga akan lebih mempercantik tampilan buku. Selain kelebihan tersebut epub juga mempunyai kelebihan lain yaitu epub bersifat friendly dan support dengan banyak perangkat,seperti komputer (diakses di google chrome, plugin firefox), Android (dengan menggunakan Ideal reader, FBReader0, iOS (ireader), Blackberry playbook, Sony Reader, dan berbagai perangakt lainnya.

Sama seperti permasalahan yang peniliti temukan dilapangan, berdasarkan tinjauan pustaka diatas didapat bahwa efektivitas blended learning hanya mencakuppenugasan konsep, tidak sampai ke kreativitas, Pada model blended learning hanya meningkatkan efektivitas dan tidak meningkatkan kreativitas mahasiswa, model blended learning 
yang dikembangakan mencakup E-Learning tidak sampai membahas efektivitas dan peningkatan kreativitas mahasiswa, Mengukur efektivitas E-
Modul tidak mencakup model pembelajaran blended learning.

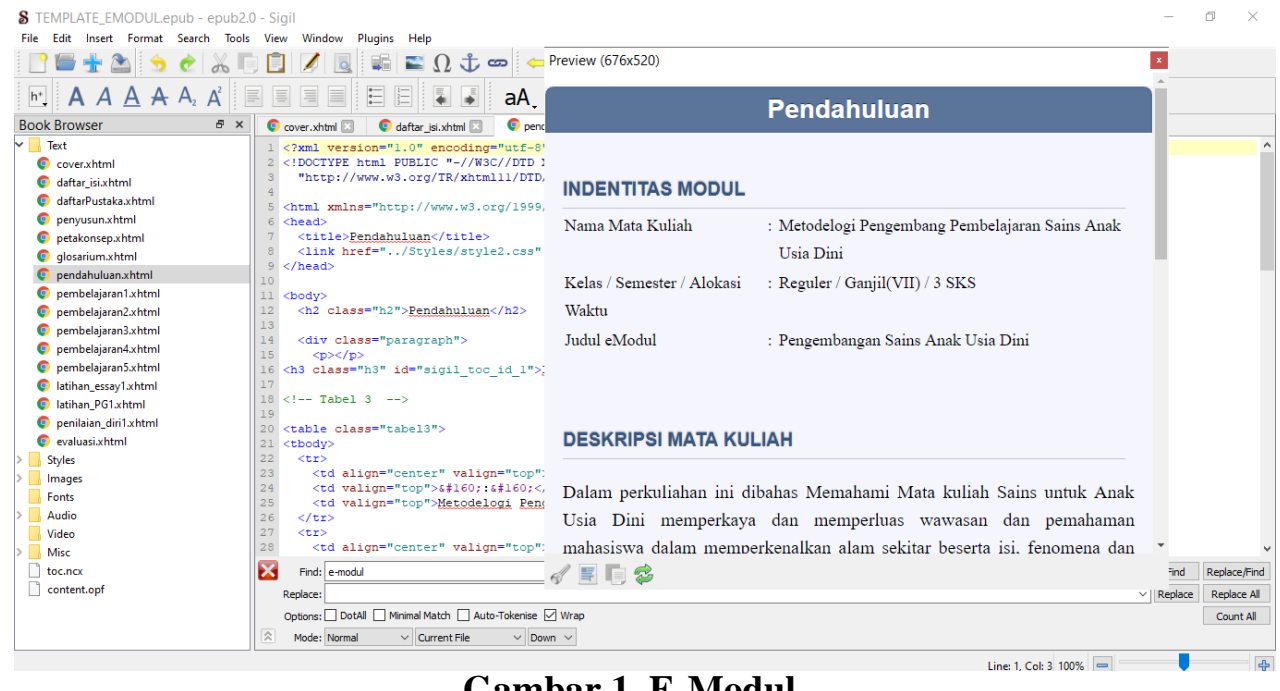

Gambar 1. E-Modul

\section{METODE PENELITIAN}

Penelitian ini menggunakan metode quasy eksperimental dengan jenis pretest-posttest group design. Desain penelitian menggunakan dua kelas, yaitu kelas eksperimen dan kelas kontrol. Perlakuan yang diberikan pada eksperimen, adalah blended learning dengan menggunakan aplikasi sigil (X1) dan pada kelas kontrol, yaitu model konvensional (X2) . Populasi penelitian ini adalah seluruh Mahasiswa Semester VII STKIP Syekh Manshur, sedangkan sample akan ditentukan menggunakan simple random secara diundi. Desain penelitian dapat dilihat pada tabel 1.

Tabel 1. Desain Penelitian

\begin{tabular}{cccc}
\hline Kelas & Pre-test & Perlakuan & Post-test \\
\hline Eksperimen & $\mathrm{O}_{1}$ & $\mathrm{X}_{1}$ & $\mathrm{O}_{1}$ \\
Kontrol & $\mathrm{O}_{3}$ & $\mathrm{X}_{2}$ & $\mathrm{O}_{3}$ \\
\hline
\end{tabular}

Desain penelitian menggunakan dua kelas, yaitu kelas eksperimen dan kelas kontrol. Perlakuan yang diberikan pada eksperimen, adalah blended learning dengan menggunakan aplikasi sigil (X1) dan pada kelas kontrol, yaitu model konvensional (X2) . Populasi penelitian ini adalah seluruh Mahasiswa Semester VII STKIP Syekh Manshur, sedangkan sample akan ditentukan menggunakan simple random secara diundi.

Variabel bebas pada penelitian ini adalah blended learning menggunakan aplikasi sigil sedangkan variabel terikat adalah kreatifitas mahasiswa terhadap mata kuliah pengembangan sain. Instrumen yang digunakan dalam penelitian ini berupa RPS perkuliahan dan e-modul yang dibuat dari aplikasi sigil sebagai pendukung blended learning, dan tes berupa soal pilihan ganda dimana memuat tiap indikator kreatifitas mahasiswa yang digunakan saat pretest dan posttest.

\section{HASIL DAN PEMBAHASAN}

Data yang dihasilkan dari penelitian ini, yaitu penguatan kreatifitas mahasiswa pada ranah kognitif. Setelah data didapat, maka dilakukan uji analisis data berupa uji N-Gain. Kemudian uji normalitas dengan kolmogrov-Smimov yang bertujuan untuk mengetahui data yang diperoleh 
berdistribusi normal atau tidak, dengan pengambilan keputusan jika nilai signifikansi $>0.05$ data terdistribusi normal dan nilai signifikansi $\leq 0.05$ data tidak terdistribusi normal. Selanjutnya uji homogenitas yang bertujuan untuk mengetahui varian dalam populasi tersebut homogen atau tidak, dan jika signifikansi $>0,05$ data homogen dan nilai signifikasnsi $\leq 0,05$ data tidak homogen. Dan tahap terakhir, yaitu uji analysis of covariance (Ancova) untuk mengetahui apakah hipotesis dapat diterima atau ditolak, dengan pengambilan keputusan jika Fhitung > Ftabel maka Ho ditolak dan H1 diterima.

Proses pembelajaran pada penelitian ini dilakukan sebanyak enam pertemuan, dimana pada pertemuan ke-1 dilakukan pretest, pertemuan ke-2 dan ke-5 dilaksanakan pembelajaran, pertemuan ke-6 dilakukan posttest. Pada kelas eksperimen diterapkan blended learning menggunakan aplikasi sigil dimana sebelum melaksanakan pembelajaran tatap muka dengan dosen, mahasiswa sudah melaksanakan pembelajaran dalam jaringan (daring) terlebih dahulu di schoology. Pada kegiatan pembelajaran daalam jaringan semua masiswa mengupload dengan jumlah post pada kegiatan pembelajaran dalam jaringan ke-1 sebanyak 175 post (dilaksanakan sebelum pertemuan ke-2), kegiatan pembelajaran dalam jaringan ke-2 sebanyak 145 post (dilaksanakan sebelum pertemuan ke-3), kegiatan pembelajaran dalam jaringan ke-3 sebanyak 172 post (dilaksanakan sebelum pertemuan ke-4), dan kegiatan pembelajaran dalam jaringan ke-4 sebanyak 119 post (dilaksanakan sebelum pertemuan ke-5). Setelah siswa mengikuti pembelajaran dalam jaringan, pembelajaran dilanjutkan secara tatap muka, sedangkan pada kelas kontrol diterapkan model pembelajaran konvensional.

Sebelum melakukan penelitian, soal terlebih dahulu diuji validitas dan reliabilitas dimana bertujuan untuk mengetahui kelayakan instrumen soal tersebut untuk digunakan dalam penelitian. Uji ini dilakukan pada mahsiswa semester VII yang berjumlah 48 mahasiswa, yang telah belajar pengembangan sains anak usia dini dengan jumlah 36 soal. Setelah dilakukan uji validitas dan reliabilita, diketahui bahwa jumlah soal yang dinyatakan valid, yaitu 36 soal dan data hasil uji reliabilitas menunjukkan nilai cronbach's alpha sebesar 0.794 yang artinya soal bersifat reliabel.

Tabel 2. Data Rata-rata Hasil Pretest Mahasiswa

\begin{tabular}{cccc}
\hline No & Parameter & Pretest Kelas Eksperimen & Pretest Kelas Kontrol \\
\hline 1 & Jumlah Mahasiswa & 23 & 25 \\
2 & Nilai Terendah & 25 & 25 \\
3 & Nilai Tertinggi & 47 & 50 \\
4 & Rata-rata Nilai & 32.66 & 32.33 \\
\hline
\end{tabular}

Berdasarkan data pada Tabel 2, rata-rata nilai pretest kelas eksperimen lebih besar dari ratarata nilai pretest kelas kontrol. Namun, tidak ada perbedaan yang signifikan antara nilai pretest kelas eksperimen dengan nilai pretest kelas kontrol, artinya kelas eksperimen dan kelas kontrol memiliki kemampuan penguasaan konsep yang sama.

Tabel 3. Data Rata-rata Hasil Posttest Mahasiswa

\begin{tabular}{cccc}
\hline No & Parameter & Pretest Kelas Eksperimen & Pretest Kelas Kontrol \\
\hline 1 & Jumlah Mahasiswa & 23 & 25 \\
2 & Nilai Terendah & 80 & 65 \\
3 & Nilai Tertinggi & 96 & 92 \\
4 & Rata-rata Nilai & 88.00 & 78.50 \\
\hline
\end{tabular}

Berdasarkan data pada Tabel 3. Rata-rata nilai posttest kelas eksperimen lebih besar dari pada rata-rata nilai posttest kelas kontrol. Grafik perolehan nilai rata-rata peningkatan kreatifitas mahasiswa dapat dilihat pada gambar 1 . 
Tabel 4. Data rata-rata N-Gain Kreatifitas Mahasiswa

\begin{tabular}{clcc}
\hline No & \multicolumn{1}{c}{ Perolehan Skor } & Kelas Eksperimen & Kelas Kontrol \\
\hline 1 & Gain Tertinggi & 65 & 60 \\
2 & Gain terendah & 37 & 24 \\
3 & Rata-rata Gain & 51 & 42 \\
4 & Kenaikan Skor Rata-rata & $51 \%$ & $42 \%$ \\
5 & Rata-rata N-Gain & 0.88 & 0.66 \\
6 & Kategori & Tinggi & Sedang \\
\hline
\end{tabular}

Berdasarkan data pada Tabel 4, nilai ratrata $\mathrm{N}-\mathrm{Gain}$ kelas eksperimen lebih tinggi dari rata- rata N-Gain kelas kontrol. Grafik perolehan nilai rata-rata $\mathrm{N}$-Gain kreatifitas mahasiswa disajikan.

Tabel 5. Data Kategori N-Gain Kreatifitas Mahasiswa

\begin{tabular}{ccccc}
\hline \multirow{2}{*}{ Kategori } & \multicolumn{2}{c}{ Kelas Eksperimen } & \multicolumn{2}{c}{ Kelas Kontrol } \\
\cline { 2 - 5 } & Jumlah & Persentase & Jumlah & Persentase \\
\hline Tinggi & 30 & $90.91 \%$ & 15 & $42.86 \%$ \\
Sedang & 9 & $9.09 \%$ & 20 & $57.14 \%$ \\
Rendah & 0 & $0.00 \%$ & 0 & $0.00 \%$ \\
\hline
\end{tabular}

Berdasarkan Tabel 5, persentase N-Gain dengan kategori tinggi pada kelas eksperimen lebih besar dari pada persentase N-Gain kelas kontrol.
Setelah mendapatkan nilai N-Gain selanjutnya dilakukan uji normalitas.

Tabel 6. Hasil Uji Normalitas Skor N-Gain Kreatifitas Mahasiswa

\begin{tabular}{lccccc}
\hline No & Parameter & \multicolumn{2}{c}{ Kelas Eksperimen } & \multicolumn{2}{c}{ Kelas Kontrol } \\
\cline { 2 - 6 } & & Pretest & posttest & Pretest & posttest \\
\hline 1 & Jumlah Siswa & 23 & 23 & 25 & 25 \\
2 & Rata-rata & 32.66 & 88.00 & 32.33 & 78.50 \\
3 & Nilai Tertinggi & 47 & 96 & 50 & 92 \\
4 & Nilai Terendah & 25 & 80 & 25 & 65 \\
5 & N-gain & \multicolumn{2}{c}{0.88} & \multicolumn{2}{c}{0.66} \\
6 & Asymp. Sig (2-tailed) & \multicolumn{2}{c}{0.631} & \multicolumn{2}{c}{0.891} \\
\hline
\end{tabular}

Berdasarkan Tabel 6, dapat diketahui bahwa nilai Asymp. Sig (2-tailed) N-gain pada kelas eksperimen adalah 0.631 sedangkan nilai Asymp. Sig (2-tailed) N-gain pada kelas kontrol adalah 0.891, dimana nilai Asymp. Sig (2-tailed) $\mathrm{N}$-gain pada kelas eksperimen dan kelas kontrol lebih dari 0.05 sehingga data $\mathrm{N}$-gain pada kelas eksperimen dan kelas kontrol berdistribusi normal.

Tabel 7. Hasil Uji Homogenitas Kreatifitas Mahasiswa

\begin{tabular}{cccc}
\hline Levene Statistic & df1 & df2 & Sign. \\
\hline 1.375 & 1 & 66 & 0.063 \\
\hline
\end{tabular}

Setelah dilakukan uji normalitas kemudian dilakukan uji homogenitas dimana berdasarkan Tabel 7, dapat diketahui bahwa nilai sig. 0.063, karena signifikasi lebih dari 0.05 maka dapat disimpulkan bahwa kedua kelompok data (data kelas eksperimen dan kelas kontrol) mempunyai varian yang sama. 
Tabel 8. Hasil Uji Ancova Kreatifitas Mahasiswa

\begin{tabular}{cccccc}
\hline Kelas & $\boldsymbol{N}$ & mean & $\boldsymbol{S . D}$ & Std. error & $\boldsymbol{f}$ \\
\hline Kelas Eksperimen & 23 & 89.94 & 4.84 & 1.06 & 15.45 \\
Kelas Kontrol & 25 & 81.57 & 7.06 & 1.03 & \\
\hline
\end{tabular}

Berdasarkan Tabel 8, uji ancova pretest dan posttest penguasaan konsep siswa dapat dinyatakan bahwa nilai $\mathrm{F}_{\text {hitung }}>\mathrm{F}_{\text {tabel }}(15.49>3.98)$ maka $\mathrm{H}_{0}$ ditolak dan $\mathrm{H}_{1}$ diterima, berarti terdapat perbedaan rata-rata penguasaan konsep siswa pada kelas eksperimen dan kelas kontrol, artinya blended learning berbasis inkuiri memberikan pengaruh yang signifikan terhadap kreativitas mahasiswa terhadap matakuliah metodelogi pembelajaran sains anak usia dini.

\section{SIMPULAN DAN REKOMENDASI}

Berdasarkan hasil penelitian dari pembahasan yang dilakukan, maka dapat disimpulkan Pembelajaran blended learning Sains Anak Usia Dini Mahasiswa PG-PAUD dengan Menggunakan Aplikasi Sigil memiliki pengaruh yang signifikan terhadap kreatifitas mahasiswa dibandingkan pembelajaran konvensional (metode ceramah). Hal ini dilihat dari nilai $\mathrm{F}_{\text {hitung }}$ $>\mathrm{F}_{\text {tabel }}(15.45>3.98)$ maka $\mathrm{H} 0$ ditolak dan $\mathrm{H} 1$ diterima dan rata-rata nilai N-Gain pada kelas eksperimen lebih tinggi dibandingkan $\mathrm{N}$-Gain pada kelas kontrol $(0,88>0,66)$, sehingga blended learning menggunakan aplikasi sigil lebih efektif untuk meningkatkan kreatifitas mahasiswa.

Berdasarkan simpulan, maka saran yang diberikan oleh peneliti, yaitu pembelajaran blended learning menggunakan aplikasi sigil dapat dijadikan salah satu alternatif bagi dosen lainnya sebagai upaya untuk meningkatkan kreatifitas mahasiswa, pada penarapannya perlu diperhatikan kreatifitas dosen dengan baik dalam penggunaan media tersebut agar penyampaian materi kepada mahasiswa lebih mudah, agar kegiatan pembelajaran semakin bermakna sebaiknya mahasiswa lebih di arahkan untuk memecahkan suatu masalah dengan proses.

\section{DAFTAR PUSTAKA}

Akhmalia, N. L. (2018). Efektivitas Blended Learning Berbasis LMS Dengan Model Pembelajaran Inkuiri Pada Materi Fluida
Statis Terhadap Penguasaan Konsep Siswa. JIPFRI, 2(2), 56-64.

Abdullah, W. (2018). Model Blended Learning dalam Meningkatkan Efektivitas Pembelajaran. Jurnal Pendidikan dan Manajemen Islam, 7(1), 50-65.

Astuti, P. (2019). Blended Learning: Studi Efektivitas Pengembangan Konten ELearning Di Perguruan Tinggi. Jurnal Pemikiran dan Penelitian Pendidikan, 17(1), 50-75.

Delianti, P. I. (2020). Efektivitas E-Modul Berbasis Project Based Learning Pada Mata Kuliah Pemrograman Visual. Jurnal Pendidikan Teknologi Kejuruan, 3(2), 200-220.

Du, C. (2011). A comparison of traditional and blended learning in introductory principles of accounting course. American Journal of Business Education, 4(9), 1-10.

Hanum, N. S. (2013). Keefektifan E-Learning Sebagaiu Media Pembelajaran (Studi Evaluasi Model Pembelajaran E-Learning Smk Telkom Sandhy Putra Purwokerto). Jurnal Pendidikan Vokasi, 3, 90-102. Https://Doi.Org/10.21831/Jpv.V3i1.1584.

Husamah. (2014). Pembelajaran Bauran, Blended Learning. Jakarta : Prestasi Pustaka Publisher.

Ishak, A., \& Deni, D. (2013). Teknologi Pendidikan. Bandung: PT Roda Karya.

Lalima, K., \& Lata, D. (2017). Blanded Learning: An Inovative Approach. Universal Journal Of Educational Reserch. 2(7), 120-135.

Linda., dan Mulyasari, A. (2020). Sikap dan Respo Anak PAUD dalam Mengenal Metamorfosis Serangga melalui Media Animasi. Jurnal Obsesi: Jurnal Pendidikan Anak Usia Dini, 5(2), 120-135.

Ruchi, S., \& Sunita, S. (2015). Implementation Of Blended Learning In Classroom: A Review Paper. Internasional Journal of 
Jurnal PAJAR (Pendidikan dan Pengajaran)

Volume 6 Nomor 1 Januari | ISSN Cetak : 2580 - 8435 | ISSN Online : 2614 - 1337

DOI : http://dx.doi.org/10.33578/pjr.v6i1.8567

Scientific And Research Publication, 11(2), 120-135.

Rusman, dkk. (2011). Pembelajaran Berbasis Teknologi Informasi dan Komunikasi. Jakarta: PT Raja Grafindo Persada.

Sagala, S. (2006). Konsep dan Makna Pembelajaran. Bandung: Penerbit Alfabeta.

Precel, K., Yoram, E., Alklai., and Yael. (2009). Pedagogical And Desain Aspect Of Blended Learning Course. International Review of Research In Open and Distance Learning, 10(2), 50-65. 